\title{
Dynamic response analysis of light weight pyramidal sandwich plates subjected to water impact
}

\author{
Hao Wang, Dr., \\ Fei Zhao, Master Graduate Student, \\ Yuan-Sheng Cheng, Dr., Professor, \\ Jun Liu, Dr., Lecturer \\ Yuan Tian, Master Graduate Student, \\ School of Naval Architecture and Ocean Engineering, \\ Huazhong University of Science and Technology, Wuhan, P.R. CHINA
}

\begin{abstract}
The fluid-solid interaction (FSI) dynamic responses for a Light Weight Pyramidal Sandwich Plate Structure (LWPSPS) under different water-entry velocities $(1 \mathrm{~m} / \mathrm{s}-6 \mathrm{~m} / \mathrm{s})$ are investigated numerically and theoretically. The characteristics of impact pressure and structure deformation are obtained by using LS-DYNA code based on the proposed 3D multi-physics (air-water-solid) FEM model. Numerical results show that the average water impact pressure of LWPSPS is much lower than that of the monolithic plate with same mass. Moreover, a phenomenon called "local air cushion" is observed for LWPSPS which does not exist for a monolithic plate. Theoretical hydroelasticity analysis demonstrates that the FSI effect of LWPSPS is weak when the ratio of water impact duration time to wet natural vibration period is greater than 4. In the study, an engineering estimation method to predict the maximum deformation of the LWPSPS is proposed, in which the total deformation is divided into two parts, i.e. local field deformation and global field deformation, and they are both computed using analytical model. Good agreement between the numerical results and ones obtained from the proposed engineering estimation method is achieved. Furthermore, the geometric variation sensitiveness analysis is also conducted.
\end{abstract}

Keywords: light weight pyramidal sandwich plate structures (LWPSPS); multi-physics numerical model; maximum deformation; quasi-static; local air cushion

\section{INTRODUCTION}

The water impact phenomenon exists in many practical engineering areas such as slamming of ship experienced boisterous weather and heavy sea, seaplane landing on water in an emergency situation et al. [1]. The significant local structural deformation may occur due to high peak water impact transient shock pressure in a very short duration [2]. Because of the severity and significance of slamming accident on naval vessels, many research efforts have been devoted during the past century. Since the late-1920s, the pioneer works of hull-water impacts have been investigated by analyzing a two-dimensional wedge impact on a calm water surface. Two of these early studies related to slamming problem of a rigid v-shaped wedge with small deadrise angle were carried out by Von Karman [3] and Wagner [4]. After then Chuang [5] performed the systematic tests with flat bottom panels in free fall against the free surface of the water in order to overcome the problem of the Von Karman asymptotic theory due to the lack of application for zero deadrise angles and to detect the effect of trapped air between the free surface and the plate on the dynamic response of the plate. He concluded that the effects of air cushion cannot be neglected if the deadrise angle was less than 3 degree in his experiments.

The equivalent rigid/quasi-static method has been widely adopted in the design rule for water impact problem due to its convenience [2]. However, the hydroelastic interaction effects should not be neglected in the design of high-speed craft [6]. Thus the hydroelastic criterion and models have been developed from 90s in [7-10]. Generally, the hydroelastic effects of water impact event are typically characterized by a relation between the loading period and the natural vibration period of structure [7-10]. Most of the previous hydroelastic interaction investigations are limited to simple steel structures such as 2D transverse section with v-shaped section of a ship-hull.

In recent years, the mechanical behavior of composite materials and sandwich structure are widely concerned [11]. Kozak [12] presented a deep and extensive view on selected problems concerning application of steel sandwich plates in shipbuilding industry. To investigate the fluid-structure interaction (FSI) during the water impact process, Qin and Batra [13] developed a hydroelastic model based on a $(3,2)$-order sandwich theory and 2D Wagner's water impact theory. The hydroelastic effect on hull's deflections and the unsteady water 

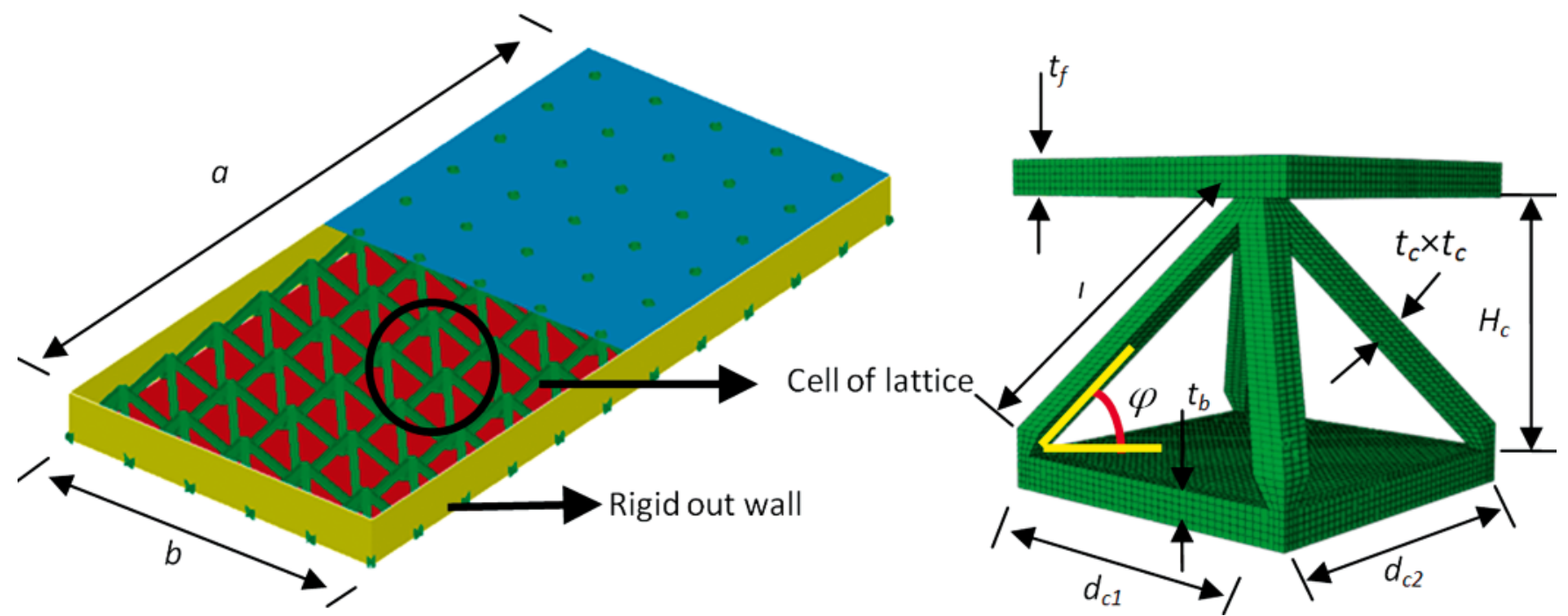

Fig. 1. Light weight sandwich plate structures with pyramidal lattice cores (LWPSPS)

impact load has been delineated. Baral et al. [14] presented results from a test simulating the water impact (slamming) loading of sandwich boat structures. Test results suggested that a novel foam core reinforced in the thickness direction with pultruded carbon fiber pins would offer significant resistance to water impact load.

The lattice structures with various core topologies have now been recognized to be attractive candidates for multifunctional ultra-light structures due to their superior properties of light weight, high specific stiffness and excellent impulsive resistant performance et al. [15-18]. As the lattice structures are periodic micro-architectured cellular solids in which the individual truss elements deform by stretching rather than by bending. Consequently, the dynamic behavior of sandwich plates with pyramidal lattice truss topology cores (LWPSPS) is quite different from other traditional constructions, including those with honeycomb core or corrugated (prismatic) core et al. Most of the previous studies focused on the static mechanism and energy absorption behavior of LWPSPS subjected to intense impact loading [15-18]. But the fluid-solid interaction (FSI) characteristics of LWPSPS subjected to water impact load are neglected, which should also be considered due to the fact that LWPSPS used in the construction of naval structures would be impacted in slamming conditions. Therefore, investigation should be undertaken on analyzing the hydroelastic pressure and deformation of LWPSPS subjected to slamming load at present.

To this end, the present study first primarily concerns on the detailed dynamic characteristic and hydroelastic mechanism of sandwich plates with pyramidal lattice truss topology cores (LWPSPS) subjected to water impact loading. The nonlinear explicit finite element (FE) software LS-DYNA is employed to build up the 3D multi-physics (air-water-solid) numerical model with the water modeled as an inviscid, compressible and nonirrotational fluid. In order to verify the FEM model, the central impact pressure values of circular solid plate are compared with experimental results. It is found that hydroelastic water impact pressure predicted by LS-DYNA agrees well with those experimental data. Furthermore, the detailed characteristics of hydroelastic water impact pressure and hull deformation of LWPSPS are summarized and compared with those of the monolithic plates with equal mass. Then the hydroelastic effect of LWPSPS is discussed theoretically by using the criteria of $2 \tau_{s} / T$ (the ratio of water impact duration time $2 \tau_{s}$ to the wet natural period $T$ ). Subsequent to calculate the maximum total elastic deformation of LWPSPS, an engineering theoretical estimation method is proposed, in which the total deformation is divided into two parts, i.e. local field deformation and global field deformation. Results from this proposed model agree well with those from the 3D FSI finite element analysis. Moreover, the individual effects of design parameters of LWPSPS such as face sheet thickness, thickness of lattice core and relative density of core on the water impact pressure and structural deformation are also investigated in the study.

\section{DESCRIPTION OF THE LWPSPS GEOMETRY MODEL}

To analyze the characteristic of LWPSPS, the first step is to choose its different constituents. LWPSPS consists of two thin face sheets attached to both sides of a light weight lattice core with an exposed area $595.1 \mathrm{~mm} \times 270.5 \mathrm{~mm}$ referred a practical monolithic flat panel of cruiser [19] (see Fig. 1). The mass of LWPSPS (case 1 - case 6) is equal to the monolithic flat panel which the thickness of this mild steel monolithic flat panel is equal to $11.11 \mathrm{~mm}$. The boundary condition of the panel can be taken as clamped [19]. Therefore, a sealed off round structure made by rigid materials (rigid out wall, see Fig. 1) is used to model clamped boundary condition (also see Fig. 1). The calculated parameters for all 22 cases are shown in Table 1.

\section{NUMERICAL SIMULATION MODEL OF LWPSPS}

The hydroelastic performance of LWPSPS subjected to water impact load is investigated using 3D multi-purpose, explicit and implicit finite element program LS-DYNA. Both Lagrangian and Eulerian solvers are available in LS-DYNA code to enable modeling of structures and fluids in a single model and to simulate the interaction between them. Interaction between the fluids and structures is achieved through arbitrary Lagrangian-Eulerian (ALE) description. In the fluid-structure coupling algorithm (typically, penalty coupling algorithm), two superimposed meshes are considered, a fixed Eulerian or ALE mesh for the fluid and a deformable Lagrangian mesh for the structure. Additionally, the ALE Multi-Material formulation is a method allowing the finite element mesh to move independently from the material flow and where each element in the mesh can contain a mixture of two or more different materials such as air and water. Therefore, ALE Multimaterial formulation and penalty coupling algorithm [20-22] are adopted in the present 3D multi-physics numerical model 
Tab. 1. Various computational cases considered

\begin{tabular}{|c|c|c|c|c|c|c|c|c|c|}
\hline Case No. & $\mathbf{a}(\mathbf{c m})$ & $\mathbf{b}(\mathbf{c m})$ & $\begin{array}{c}\mathbf{d}_{\mathrm{c} 1}=\mathbf{d}_{\mathrm{c} 2} \\
(\mathrm{~mm})\end{array}$ & $\tan (\varphi)$ & $\mathbf{t}_{\mathrm{f}}(\mathbf{m m})$ & $\mathbf{t}_{b}(\mathbf{m m})$ & $\mathbf{H}_{\mathrm{c}}(\mathbf{m m})$ & $\mathbf{t}_{\mathrm{c}} \times \mathbf{t}_{\mathrm{c}}(\mathbf{m m} \times \mathbf{m m})$ & $\mathbf{v}(\mathbf{m} / \mathbf{s})$ \\
\hline $\mathrm{C} 1$ & 59.51 & 27.05 & 54.10 & 1.00 & 4.219 & 4.219 & 38.25 & $6.00 \times 6.00$ & 5 \\
\hline $\mathrm{C} 2$ & 59.51 & 27.05 & 54.10 & 1.00 & 4.219 & 4.219 & 38.25 & $6.00 \times 6.00$ & 1 \\
\hline $\mathrm{C} 3$ & 59.51 & 27.05 & 54.10 & 1.00 & 4.219 & 4.219 & 38.25 & $6.00 \times 6.00$ & 2 \\
\hline $\mathrm{C} 4$ & 59.51 & 27.05 & 54.10 & 1.00 & 4.219 & 4.219 & 38.25 & $6.00 \times 6.00$ & 3 \\
\hline $\mathrm{C} 5$ & 59.51 & 27.05 & 54.10 & 1.00 & 4.219 & 4.219 & 38.25 & $6.00 \times 6.00$ & 4 \\
\hline $\mathrm{C} 6$ & 59.51 & 27.05 & 54.10 & 1.00 & 4.219 & 4.219 & 38.25 & $6.00 \times 6.00$ & 6 \\
\hline $\mathrm{C} 7$ & 59.51 & 27.05 & 54.10 & 1.00 & 4.219 & 2.219 & 38.25 & $6.00 \times 6.00$ & 5 \\
\hline $\mathrm{C} 8$ & 59.51 & 27.05 & 54.10 & 1.00 & 4.219 & 3.219 & 38.25 & $6.00 \times 6.00$ & 5 \\
\hline C9 & 59.51 & 27.05 & 54.10 & 1.00 & 4.219 & 5.219 & 38.25 & $6.00 \times 6.00$ & 5 \\
\hline $\mathrm{C} 10$ & 59.51 & 27.05 & 54.10 & 1.00 & 4.219 & 6.219 & 38.25 & $6.00 \times 6.00$ & 5 \\
\hline $\mathrm{C} 11$ & 59.51 & 27.05 & 54.10 & 1.00 & 2.219 & 4.219 & 38.25 & $6.00 \times 6.00$ & 5 \\
\hline $\mathrm{C} 12$ & 59.51 & 27.05 & 54.10 & 1.00 & 3.219 & 4.219 & 38.25 & $6.00 \times 6.00$ & 5 \\
\hline $\mathrm{C} 13$ & 59.51 & 27.05 & 54.10 & 1.00 & 5.219 & 4.219 & 38.25 & $6.00 \times 6.00$ & 5 \\
\hline C14 & 59.51 & 27.05 & 54.10 & 1.00 & 6.219 & 4.219 & 38.25 & $6.00 \times 6.00$ & 5 \\
\hline $\mathrm{C} 15$ & 59.51 & 27.05 & 54.10 & 0.48 & 4.219 & 4.219 & 18.25 & $6.00 \times 6.00$ & 5 \\
\hline $\mathrm{C} 16$ & 59.51 & 27.05 & 54.10 & 0.74 & 4.219 & 4.219 & 28.25 & $6.00 \times 6.00$ & 5 \\
\hline $\mathrm{C} 17$ & 59.51 & 27.05 & 54.10 & 1.26 & 4.219 & 4.219 & 48.25 & $6.00 \times 6.00$ & 5 \\
\hline $\mathrm{C} 18$ & 59.51 & 27.05 & 54.10 & 1.52 & 4.219 & 4.219 & 58.25 & $6.00 \times 6.00$ & 5 \\
\hline C19 & 59.51 & 27.05 & 54.10 & 1.00 & 4.219 & 4.219 & 38.25 & $5.00 \times 5.00$ & 5 \\
\hline $\mathrm{C} 20$ & 59.51 & 27.05 & 54.10 & 1.00 & 4.219 & 4.219 & 38.25 & $5.50 \times 5.50$ & 5 \\
\hline $\mathrm{C} 21$ & 59.51 & 27.05 & 54.10 & 1.00 & 4.219 & 4.219 & 38.25 & $6.50 \times 6.50$ & 5 \\
\hline $\mathrm{C} 22$ & 59.51 & 27.05 & 54.10 & 1.00 & 4.219 & 4.219 & 38.25 & $7.00 \times 7.00$ & 5 \\
\hline
\end{tabular}

to simulate water impact phenomenon. The detailed description of ALE formulation and penalty coupling algorithm is provided in References [20-21].

\section{Constitutions of solid}

The LWPSPS is made of mild steel for marine industry [23]. For the constitutive law of this steel, the kinematic hardening rule and elastic-linear work-hardening model are adopted in the analysis. And the materials properties are described as follows [19]:

- Modulus of elasticity E = 206.85 GPa;

- Yielding strength $\sigma_{\mathrm{Y}}=206.85 \mathrm{MPa}$;

- Density $\rho_{\mathrm{s}}=7850 \mathrm{~kg} / \mathrm{m}^{3}$;

- Poisson ratio $v=0.3$;

- Tangential modulus $\mathrm{E}_{\mathrm{t}}=250 \mathrm{MPa}$.

Generally, the effect of strain rate is sufficiently important to analyze the dynamic responses of structures. The plastic kinematic hardening description is commonly used in these impact analyses, which is a strain rate dependent elastic-plastic model. In the analysis, strain rate is taken into account by using the Cowper-Symonds model [23] which scales the yield stress by the strain rate dependent factor. According to Ref. [24], the strain-rate sensitivity model provides a reasonably good representation of test results up to strain rate of $1000 \mathrm{~S}^{-1}$. Eq. (1) shows the relationship between the stress ratio and the plastic strain rate [23]. The dynamic yield stress $\sigma_{Y D}$ is a function of plastic strain rate and can be expressed as follow:

$$
\frac{\sigma_{\mathrm{YD}}\left(\dot{\varepsilon}_{\mathrm{pl}}\right)}{\sigma_{\mathrm{Y}}}=1+\left(\frac{\dot{\varepsilon}_{\mathrm{pl}}}{\mathrm{D}_{\mathrm{cs}}}\right)^{1 / \mathrm{q}}
$$

where the Cowper-Symonds strain rate parameters $D_{c s}$ and $q$ have values of $40.4 \mathrm{~S}^{-1}$ and 5 for mild steel in this study [23], and $\sigma_{\mathrm{Y}}$ is the initial static yield stress of the material.

\section{Equation of state}

In general, the equation of state (EOS) specified for water is a Gruneisen equation and it can be used to calculate the internal characteristics of seawater. It properly handles wave propagation 


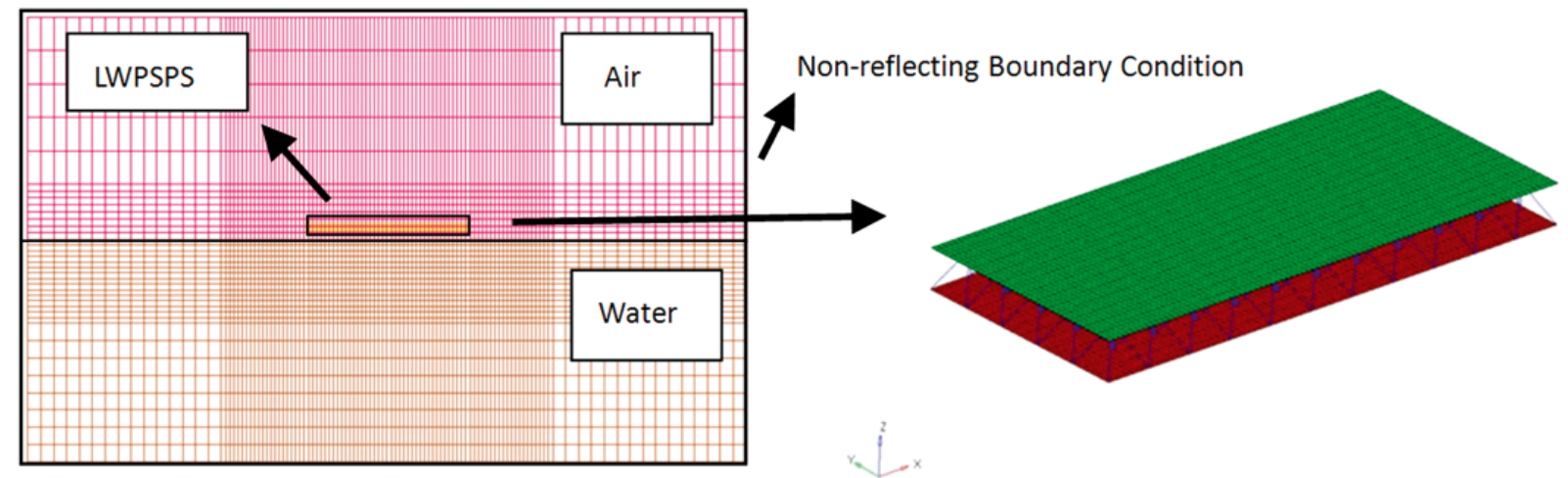

Fig. 2. 3D multi-physics finite element model of air, water and LWPSPS

phenomenon in water impact events by incorporating a nonlinear shock velocity-particle velocity relationship. And this equation addresses fluid under tension/compression which can capture cavitation phenomena in seawater. The Gruneisen EOS is defined as follow:

$$
\mathrm{p}_{\text {water }}=\frac{\rho_{\mathrm{w} 0} \mathrm{C} \mu\left[1+\left(1-\frac{\gamma_{0}}{2}\right) \mu-\left(\frac{\eta}{2}\right) \mu^{2}\right]}{\left[1-\left(\mathrm{S}_{1}-1\right) \mu-\mathrm{S}_{2} \frac{\mu^{2}}{(1+\mu)}-\mathrm{S}_{3} \frac{\mu^{3}}{(1+\mu)^{2}}\right]}+
$$

where $\mathrm{e}$ is the internal energy per unit volume, $\mathrm{C}$ is the intercept of the us-up curve, $\mathrm{S}_{1}, \mathrm{~S}_{2}$, and $\mathrm{S}_{3}$ are the coefficients of the slope of the us-up curve, $\gamma_{0}$ is the Gruneisen gamma, and $\eta$ is the first-order volume correction to $\gamma_{0}$. The constants $C, S_{1}, S_{2}, S_{3}$, $\gamma_{0}$, and $\eta$ et al. are all input constant parameters [20]: reference sea water density $\rho_{\mathrm{w} 0}=1025 \mathrm{~kg} / \mathrm{m}^{3}$; sea water temperature $\mathrm{T}=20^{\circ} \mathrm{C}$; speed of sound in water $\mathrm{C}_{0}=1480 \mathrm{~m} / \mathrm{s}$; dynamic viscosity coefficient $v_{\mathrm{s}}=1.13 \mathrm{E}-03 \mathrm{~N} \cdot \mathrm{s} / \mathrm{m}^{2}$; intercept of us-up curve $\mathrm{C}=2417 \mathrm{~m} / \mathrm{s}$; Gruneisen coefficient $\mathrm{S}_{1}=1.41, \mathrm{~S}_{2}=0$, $S_{3}=0$; Gruneisen gamma $\gamma_{0}=1.0$; first-order volume correction to gamma $\eta=0$; internal energy of water per specific volume $\mathrm{e}=1.89 \mathrm{E}+06 \mathrm{~J} / \mathrm{m}^{3}$; related volume at time 0 to reference specific volume is equal to 1 .

And the compression of sea water is defined in terms of relative volume $\mathrm{V}$ as:

$$
\mu=\frac{1}{V}-1=\frac{\rho_{\mathrm{w}}}{\rho_{\mathrm{w} 0}}-1
$$

where $\rho_{\mathrm{w} 0}$ is the reference sea water density; $\rho_{\mathrm{w}}$ is the overall sea water density.

In LS-DYNA, the perfect gas law (gamma law) is used as the equation of state for air. This equation of state is given by [20]:

$$
\mathrm{p}_{\text {air }}=(\gamma-1) \frac{\rho_{\text {air }}}{\rho_{\text {air } 0}} \mathrm{e}_{0}
$$

where $\rho_{\text {air }}$ is the overall air density for perfect gas, $e_{0}$ is the internal energy of air per unit mass and $\gamma$ is the adiabatic expansion coefficient. Here, $\gamma=1.40, \mathrm{e}_{0}=2.11 \mathrm{E}+06 \mathrm{~J} / \mathrm{kg}$ and $\rho_{\text {air } 0}=1.239 \mathrm{~kg} / \mathrm{m}^{3}$ are conducted in the present study for perfect gas.

\section{Finite element model and verification}

Fig. 2 shows the 3D multi-physics finite element model adopted in the simulation. The face sheets of LWPSPS are modeled as Lagrangian Belytschko-Tsay shell elements (see
Fig. 2), where the lightweight lattice cores are modeled as Hughes-Liu beam elements, seawater and air are modeled as Euler solid elements (see Fig. 2). The dimensions of the water region for the $3 \mathrm{D}$ finite element model are $2.6 \times 1.3 \times 0.8 \mathrm{~m}^{3}$ while those of the air region are also $2.6 \times 1.3 \times 0.8 \mathrm{~m}^{3}$.

In general, it is known that the results based on ALE algorithm are sensitive to the Euler mesh density. The Euler mesh needs to be fine enough to capture the highest gradients in the pressure fields, yet a coarser mesh is favorable in terms of computational cost. Furthermore, for the selection of the contact stiffness in penalty based contact algorithm, it is required that the maximum pressures are approximately known ahead. So the non-physical contact penetration can be controlled [20-22].

Hence, the Euler mesh density and parameters of contact penetration stiffness in simulation are firstly verified by water impact experimental results provided in literature [25]. With four different impact velocities, a circular monolithic plate (made by 6061-T6 aluminum alloy, thickness $=11.5 \mathrm{~mm}$, diameter $=200.0 \mathrm{~mm}$ ) free falls on to the water surface. The simulation model of this circular plate is similar to that of LWPSPS, as shown in Fig. 2. The other detailed description of these water impact experiments can be found in reference [25]. The material constants for 6061-T6 aluminum alloy conducted in the numerical validation analysis of this circular plate model are: $\mathrm{E}=68.94 \mathrm{GPa}, \mathrm{E}_{\mathrm{t}}=0.7 \mathrm{GPa}, v=0.33, \rho_{\mathrm{al}}=2700 \mathrm{~kg} / \mathrm{m}^{3}$ and $\sigma_{\mathrm{Y}}=352 \mathrm{MPa}$ [26].

Water impact velocities employed in these experiments are $1.40 \mathrm{~m} / \mathrm{s}, 1.98 \mathrm{~m} / \mathrm{s}, 2.43 \mathrm{~m} / \mathrm{s}$ and $2.80 \mathrm{~m} / \mathrm{s}$ respectively. When the Euler mesh size is about $1.0 \mathrm{~cm}$, the high frequent oscillations in the pressure curve are not obvious, and the peak FSI pressure results are found acceptable compared with experimental results in Table 2 .

Tab. 2. Tabulated central hydroelastic pressure results for aluminum alloy plates

\begin{tabular}{|c|c|c|c|c|c|}
\hline Case & $\begin{array}{c}\mathbf{1 . 4 0} \\
{[\mathbf{m} / \mathbf{s}]}\end{array}$ & $\begin{array}{c}\mathbf{1 . 9 8} \\
{[\mathbf{m} / \mathbf{s}]}\end{array}$ & $\begin{array}{c}\mathbf{2 . 4 3} \\
{[\mathbf{m} / \mathbf{s}]}\end{array}$ & $\begin{array}{c}\mathbf{2 . 8 0} \\
{[\mathbf{m} / \mathbf{s}]}\end{array}$ & Average \\
\hline $\begin{array}{c}\text { Pressure- } \\
\text { Experiment } \\
{[\mathrm{KPa}][25]}\end{array}$ & 56.90 & 76.52 & 105.95 & 138.45 & - \\
\hline $\begin{array}{c}\text { Pressure- } \\
\text { Numerical } \\
{[\mathrm{KPa}]}\end{array}$ & 62.07 & 76.66 & 114.40 & 151.02 & - \\
\hline Relative Error & $9.08 \%$ & $0.18 \%$ & $7.97 \%$ & $9.07 \%$ & $6.58 \%$ \\
\hline
\end{tabular}

Water impact FSI pressure

The empirical expressions are commonly used to describe the hydrodynamic impact pressure. Yuzuru (1954) [25], Chuang 
(1970) [5] and Jones (1973) [27] all proposed typical equations which are as follows:

1. Yuzuru (1954) [25]

$$
\mathrm{p}_{\max }=\mathrm{kv}^{1.56}
$$

2. Chuang (1970) [5]

$$
\mathrm{p}_{\max }=\mathrm{A}=\mathrm{Bv}
$$

3. Jones (1973) [27]

$$
\mathrm{p}_{\max }=\mathrm{kV}^{2}
$$

Notations A, B and k in Eqs. (5) are constants based on the geometry dimensions and material properties of structure. It can be observed that the main difference of Eqs. (5) is the selection of the powers of velocity $\mathrm{v}$. The unified expression of Eqs. (5) is below:

$$
\mathrm{p}_{\max }-\mathrm{p}_{\infty}=\mathrm{kV}^{\alpha}
$$

or:

$$
\ln \left(\mathrm{p}_{\max }-\mathrm{p}_{\infty}\right)=\ln (\mathrm{k})+\alpha \ln (\mathrm{v})
$$

where $\mathrm{p}_{\infty}$ is atmosphere pressure; $\alpha$ and $\mathrm{k}$ are also the parameters based the geometry dimensions and material properties of structure.

The water impact loading pressure of LWPSPS in terms of $\mathrm{Ln}$ (v) for six different free fall velocities (C1-C6) are shown in Fig. 3. For comparison, the numerical results of monolithic flat panels with the same mass are also given in Fig. 3. According to the simulation results plotted in Fig. 3, the following observations can be drawn:

- The performance of central water impact pressure for both monolithic plate and LWPSPS follows a linear trend, as determined from a least square linear fit:

$$
\begin{aligned}
& \ln \left(\mathrm{p}_{\max }-\mathrm{p}_{\infty}\right)=3.75+1.64 \ln (\mathrm{v}) \\
& \ln \left(\mathrm{p}_{\max }-\mathrm{p}_{\infty}\right)=4.05+1.44 \ln (\mathrm{v})
\end{aligned}
$$

By means of the least square linear fit, the average FSI pressure for monolithic plate and LWPSPS is also determined:

$$
\begin{aligned}
& \ln \left(\mathrm{p}_{\max }-\mathrm{p}_{\infty}\right)=2.71+2.03 \ln (\mathrm{v}) \\
& \ln \left(\mathrm{p}_{\max }-\mathrm{p}_{\infty}\right)=2.63+1.69 \ln (\mathrm{v})
\end{aligned}
$$

- During the hull-water impact, the advantage of LWPSPS deceasing peak pressure amplitude on entire FSI surface at high impact velocity $(>2 \mathrm{~m} / \mathrm{s})$ is observed. But the difference of water impact pressure characteristics between LWPSPS and monolithic plate located in the central point is insignificant.

- The values of $\alpha$ and $\mathrm{k}$ are constants though the range of water impact pressure varies widely. This conclusion has been identified by previous experimental results of solid plate $[5,25,27]$. Furthermore, the value of $\alpha$ of average FSI pressures for LWPSPS is close to 1.69, which is lower than the one of monolithic plate $(=2.03)$.

As a summary, the impulsive shapes are shown in Fig. 4. A more precise two parameters parabolic mathematical expression is defined as follows, which is different from the expressions conducted in the literature [27-29]:

$$
\mathrm{p}(\mathrm{t})= \begin{cases}\mathrm{K}_{1} \mathrm{t}^{2}+\mathrm{K}_{2} \mathrm{t}, & 0 \leq \mathrm{t} \leq 2 \tau_{\mathrm{s}} \\ 0, & 2 \tau_{s} \leq \mathrm{t}\end{cases}
$$

where:

$$
\mathrm{K}_{1}=-\frac{\mathrm{p}_{\max }}{\tau_{\mathrm{s}}^{2}}, \mathrm{~K}_{2}=\frac{2 \mathrm{p}_{\max }}{\tau_{\mathrm{s}}}, \mathrm{p}_{\max }=\mathrm{kv}^{\alpha}
$$

where $p_{\max }$ is the maximum value of water impact pressure impulse; $2 \tau_{\mathrm{s}}$ is the duration time of impulse.

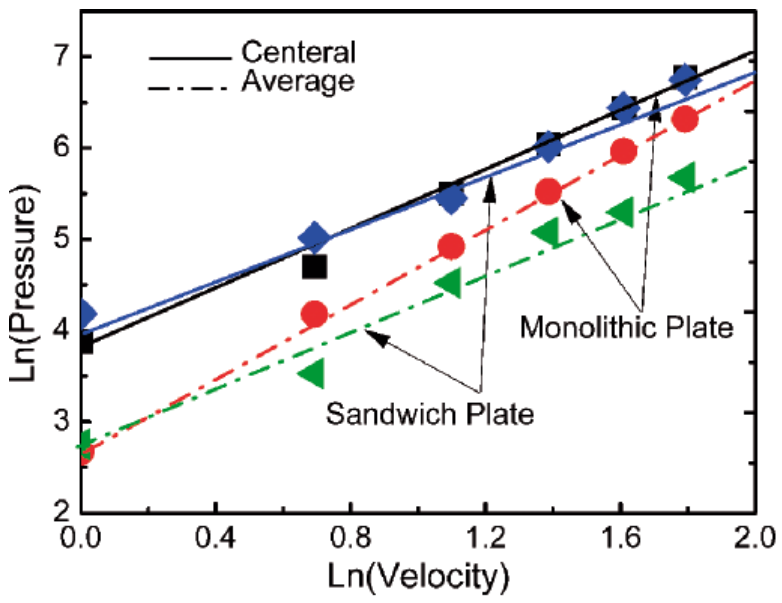

Fig. 3. Peak pressure of monolithic plate and LWPSPS at different water impact velocity

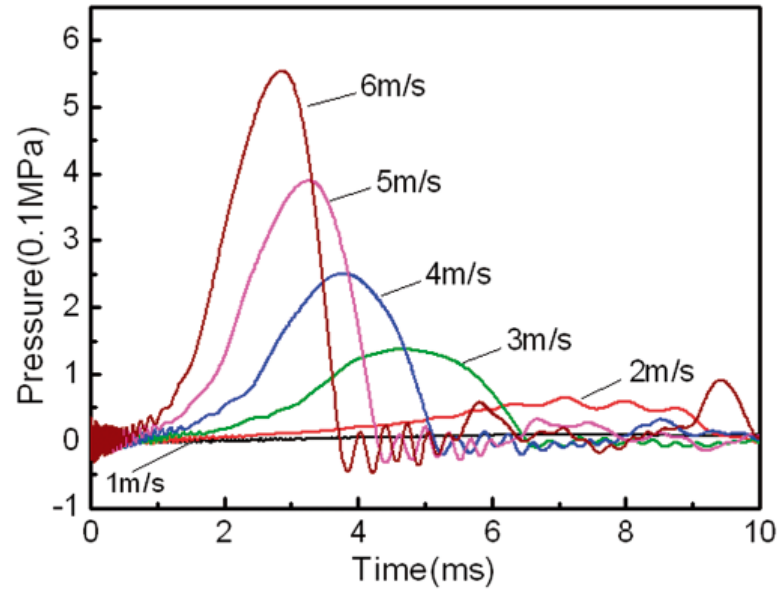

a) Monolithic plate

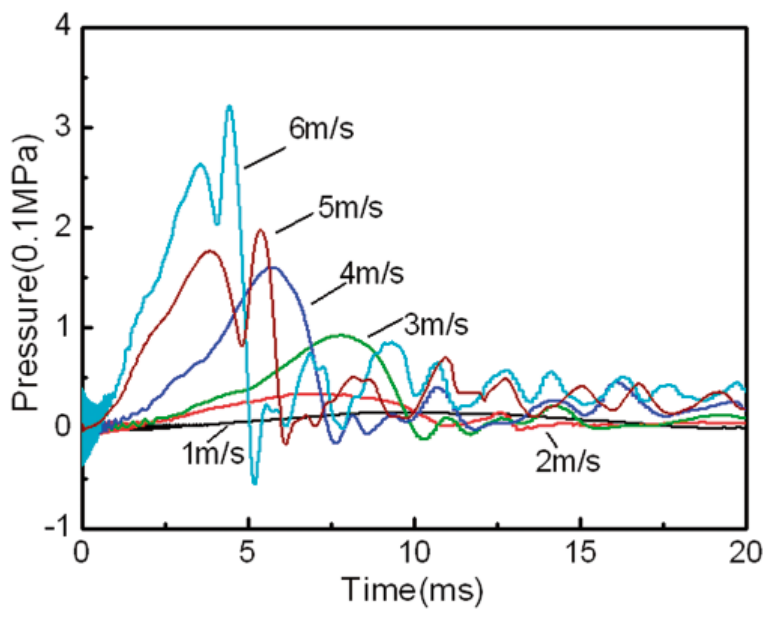

b) LWPSPS

Fig. 4. Pressure time history of water impact for monolithic plate and LWPSPS (C1-C6)

If the peak impulsive pressure $p_{\max }$ is observed in Eqs. (7), the objective now is to determine the duration time of impulsive $2 \tau_{\mathrm{s}}$. The pulse pressure loading time of circular plate has been suggested by Chuang [4] as following estimation: 


$$
2 \tau_{\mathrm{s}} \cong \frac{4 \mathrm{r}}{\mathrm{C}_{0}}
$$

where $r$ is the radius of circular plate; $\mathrm{C}_{0}$ is the sound speed of air $\left(\mathrm{C}_{0}=340 \mathrm{~m} / \mathrm{s}\right)$. For rectangular plates, the peak pulse pressure loading time can be modified as [4]:

$$
2 \tau_{\mathrm{s}} \cong \frac{2 \sqrt{\mathrm{a}^{2}+\mathrm{b}^{2}}}{\mathrm{C}_{0}}
$$

It is obtained that the $2 \tau_{\mathrm{s}}$ of monolithic panel in the present research is nearly $4.0 \mathrm{~ms}$ from Eq. (9b). This estimation is consisted with the numerical results in Fig. 4. Furthermore, the duration time of impulse $2 \tau_{\mathrm{s}}$ is less sensitive to the variation of water impact velocity. As shown in Fig. 4, the water impact loading time of LWPSPS is longer than that of solid plate. Based on the numerical results, a modified estimation of $2 \tau_{\mathrm{s}}$ for LWPSPS is given by:

$$
2 \tau_{\mathrm{s}} \cong \frac{(2.1 \sim 2.6) \sqrt{\mathrm{a}^{2}+\mathrm{b}^{2}}}{\mathrm{C}_{0}}
$$

It is observed that the impulsive duration time $2 \tau_{\mathrm{s}}$ for all cases of LWPSPS is $4.50 \mathrm{~ms}-5.50 \mathrm{~ms}$ from Eq. (10).

Moreover, the results obtained from fluid materials volume distribution iso-surface in initial water entry period show that an interesting phenomenon - "local air cushion" exists during the initial water impact duration (see the dashed line in Fig. 5). But this interesting phenomenon does not exist in initial water impact period of monolithic plate. This local cushion is mainly caused by lattice cell local deformation which has significant effects on the water impact pressure and dynamic responses of LWPSPS. Because of the existence of this local air cushion, which plays a role as a buffer device, the peak value of average FSI pressure of contacted-water wet face sheet of LWPSPS is much lower than that of monolithic plate (see Fig. 3). Additionally, as shown in Fig. 4b, the high frequency components of hydroelastic pressure curve for LWPSPS are excited by the local cell deformation.

\section{THEORETICAL ANALYSIS: HYDROELASTICITY ASSESSMENT AND DEFORMATION CALCULATION}

\section{Basic vibration characteristics of monolithic plate and LWPSPS}

In order to evaluate the hydroelastic effects in section 4.2 , the fundamental frequency $\mathrm{f}\left(\mathrm{f}_{\mathrm{s}}\right)$ of bending vibration mode for solid plate (LWPSPS) with clamped supported boundaries is calculated firstly. The fundamental frequency $f$ of bending vibration modes of a clamped monolithic plate [30] is given by:

$$
2 \pi f=\omega=\sqrt{\frac{16 \pi^{4}}{9} \frac{D}{m_{0}}\left(\frac{3}{a^{4}}+\frac{3}{a^{4}}+\frac{2}{a^{2} b^{2}}\right)}
$$

where $\mathrm{m}_{0}$ is the mass unit area, $\mathrm{D}$ is the bending stiffness of plate, $a$ and $b$ are the length and the width of plate. In the present analysis, the fundamental frequency $f$ of this monolithic plate is $938 \mathrm{~Hz}$ and the analytical result is in good agreement with the FEM simulation result $(922 \mathrm{~Hz})$.

Because of the discrete characteristics of lattice truss core, the calculation of the natural frequency of LWPSPS is much more complicated. Usually, the generalized equivalent model can be mostly used in the preliminary analysis stage of design process. It can be used to reduce the time spent for the analysis of LWPSPS. The homogenization method also makes it possible to avoid the problems involved in heterogeneities. Here, a new equivalent method to calculate the fundamental bending vibration frequencies of LWPSPS is proposed as follows (Fig. 6):

- Step 1: calculate the equivalent shear rigidity of LWPSPS lattice core.

There are a few methods to calculate the equivalent shear constant of lattice materials. Liu [31] proposed a matrix displacement method of lattice truss based on the small displacement assumption. Therefore, this homogenization method is employed here to calculate the shear rigidity of LWPSPS lattice core as follows:

$$
\begin{gathered}
\bar{\rho}_{\mathrm{c}}=\rho_{\mathrm{s}} \frac{2 \mathrm{t}_{\mathrm{c}}^{2}}{1^{2} \cos ^{2} \varphi \sin \varphi} \\
\mathrm{E}_{\mathrm{c}}=\mathrm{E} \bar{\rho}_{\mathrm{c}} \sin ^{4} \varphi \\
\mathrm{C}_{\mathrm{G}}=\frac{\left[\mathrm{H}_{\mathrm{c}}+\left(\mathrm{t}_{\mathrm{f}}+\mathrm{t}_{\mathrm{b}}\right) / 2\right]^{2}}{\mathrm{H}_{\mathrm{c}}}\left[\begin{array}{ll}
\mathrm{C}_{55}^{\mathrm{H}} & \mathrm{C}_{54}^{\mathrm{H}} \\
\mathrm{C}_{45}^{\mathrm{H}} & \mathrm{C}_{44}^{\mathrm{H}}
\end{array}\right]
\end{gathered}
$$

where $\overline{\rho_{c}}$ is the relative density of this lattice core [32], $E_{c}$ is the normal modulus of LWPSPS core [32], $C_{G}$ is the transverse shear rigidity matrix of LWPSPS core (the detailed expressions of the homogenized moduli of lattice core $\mathrm{C}_{\alpha \beta}^{\mathrm{H}},(\alpha, \beta=4,5)$ can be found in literature [31]), the definitions of $1, \varphi$ and $t_{c}$ can be seen in Fig. 1 and $\rho_{\mathrm{s}}$ is the material density of the cell structure.

Step 2: calculate the bending rigidity of LWPSPS. For the thin face sheets of LWPSPS, only bending deformation is considered (the bending stiffness $D_{f}$ of face
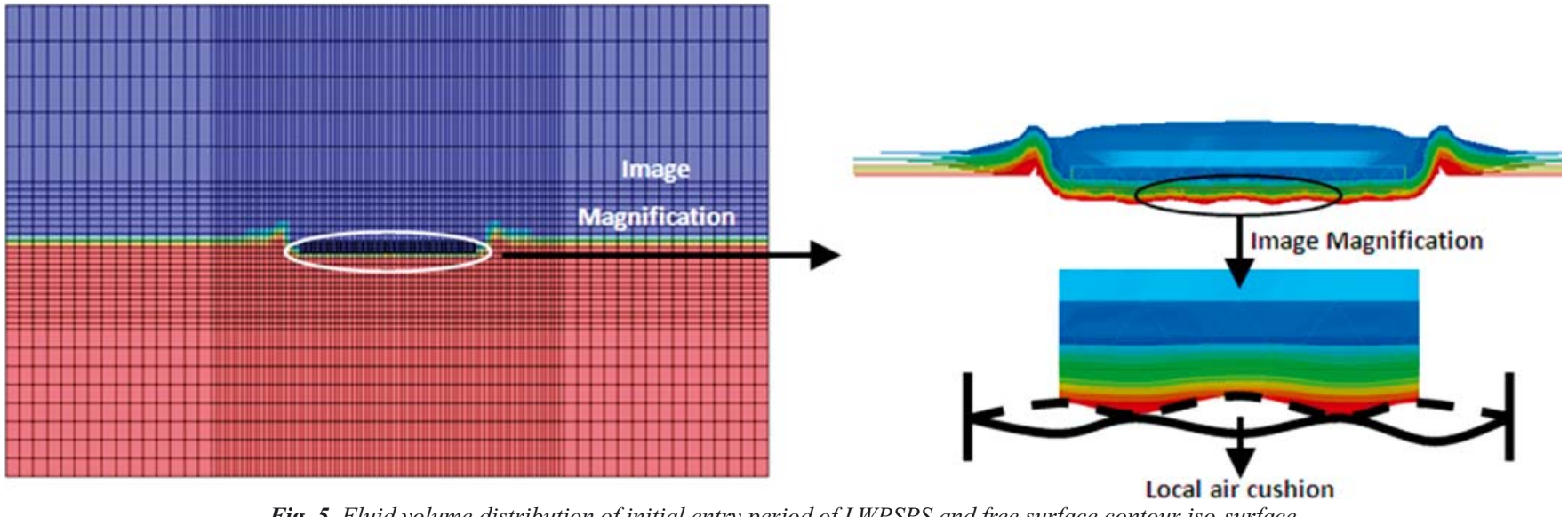

Fig. 5. Fluid volume distribution of initial entry period of LWPSPS and free surface contour iso-surface 

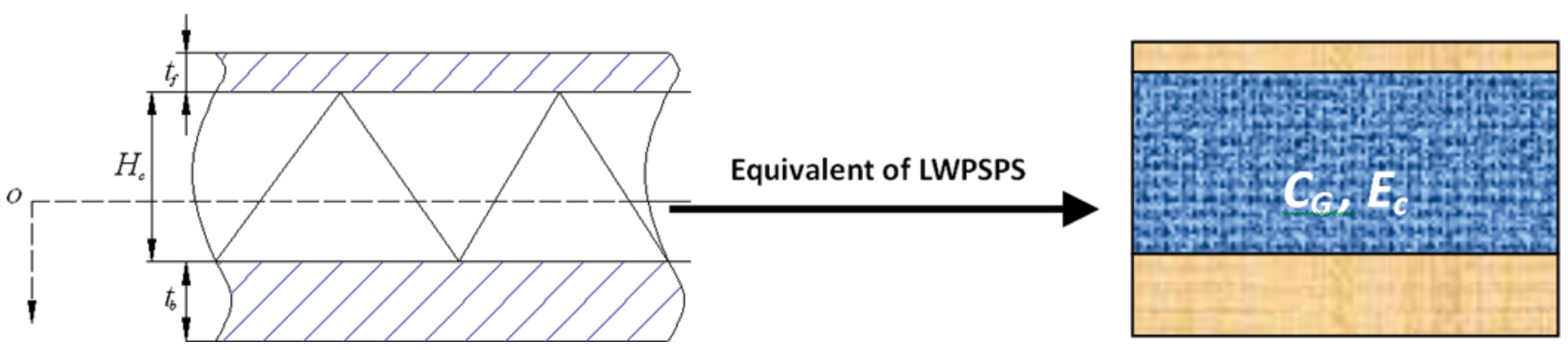

Fig. 6. Equivalent model of LWPSPS

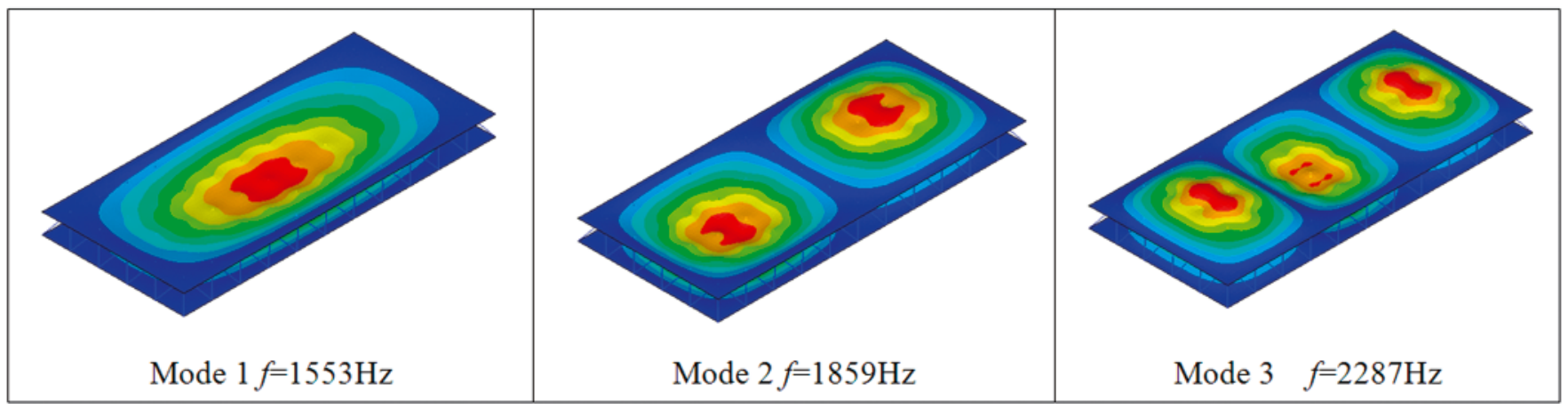

Fig. 7. The 1st - 3st bending vibration modals of LWPSPS (Case1)

sheets is included). The bending stiffness of sandwich panel (LWPSPS) with face layers of non-equal thickness [33] is given by:

$$
\mathrm{D}_{1}=\frac{\mathrm{E}\left(\left(\mathrm{H}_{\mathrm{c}}+\mathrm{t}_{\mathrm{f}}+\mathrm{t}_{\mathrm{b}}\right)^{3}-\mathrm{H}_{\mathrm{c}}^{3}\right)}{12\left(1-\mathrm{v}^{2}\right)}
$$

$$
\cdot\left(1-\frac{3\left(\mathrm{t}_{\mathrm{f}}-\mathrm{t}_{\mathrm{b}}\right)^{2}}{\left(1+\frac{\mathrm{H}_{\mathrm{c}}}{\left(\mathrm{H}_{\mathrm{c}}+\mathrm{t}_{\mathrm{f}}+\mathrm{t}_{\mathrm{b}}\right)}+\frac{\left(\mathrm{H}_{\mathrm{c}}+\mathrm{t}_{\mathrm{f}}+\mathrm{t}_{\mathrm{b}}\right)}{\mathrm{H}_{\mathrm{c}}}\right)\left(\mathrm{t}_{\mathrm{f}}+\mathrm{t}_{\mathrm{b}}\right)^{2}}\right)
$$

The meanings of all nomenclatures are given in Fig. 1 and Fig. 6.

- Step 3: calculate the natural frequency of LWPSPS with clamped supported boundary conditions.

If the bending rigidity and shear rigidity of LWPSPS are obtained in step 1 and step 2, the last step is to calculate the natural frequency with clamped supported boundary conditions. In this key step, an approximate method [34] is adopted to analyze the fundamental vibration frequency of the LWPSPS. Due to the complexity of approximate mathematic equations, only the calculation results are given here. Detailed steps of solving approximate equations can be found in literature [34-35].

The first modal frequency $\mathrm{f}_{\mathrm{s}}$ of LWPSPS (Case 1) based on the equivalent-approximate method is $1698 \mathrm{~Hz}$ which is close to the FEM result $(1553 \mathrm{~Hz})$ in Fig. 7 (the error is $9.34 \%$ ). It must be pointed out that the equivalent-approximate method is more accurate in high frequencies [35]. Thus, the error between FEM numerical result and equivalent approximate result for the second (third) bending vibration frequency is less than $5 \%$.

\section{Analysis of hydroelastic effect}

As mentioned in the previous section, the transient response of a free fall structure subjected to hull-water impact loading is greatly complicated. The evaluation of hydroelastic (FSI) effect is an important part of this investigation topic. In Ref. [8], the hydroelastic effect indicator is formulated by Bereznitski:

$$
\mathrm{R}_{\mathrm{B}}=\mathrm{T}_{\mathrm{LPB}} / \mathrm{T}_{\mathrm{NPB}}
$$

where $\mathrm{T}_{\mathrm{LPB}}$ is the water impact loading time, and $\mathrm{T}_{\mathrm{NPB}}$ is the first dry natural period of vibration. Compared Eq. (14) with the definition $2 \tau_{\mathrm{s}} \mathrm{f}_{\mathrm{s}}$ (or $2 \tau_{\mathrm{s}} \mathrm{f}$ ), it is found that these two expressions have the same physical meaning. Bereznitski [8] concluded that the hydroelastic effects become important when a ratio $R_{B}$ (or $2 \tau_{\mathrm{s}} \mathrm{f}_{\mathrm{s}}$ ) $<\mathrm{R}_{\text {Blim }}$, where $\mathrm{R}_{\text {Blim }} \approx 2.0$.

Jones also pointed out that the responses of structure can be seen as quasi-static if the duration of water impact loading time $2 \tau_{\mathrm{s}}$ is much longer than the first natural bending vibration period $\mathrm{T}\left(2 \tau_{\mathrm{s}}>\mathrm{T}\right)$ [27]. In fact, for a single-degree springmass system (SDOF), the deformations calculated for the same load applied statically agree with the corresponding maximum dynamic deformations to within approximately $17 \%$ when $2 \tau_{\mathrm{s}} / \mathrm{T}>1.75$ [36].

According to Eq. (11), the responses of this clamped plate can be seen as quasi-static $\left(2 \tau_{\mathrm{s}} \mathrm{f} \cong 4.2-5.2>2.0\right)$. For LWPSPS, the multiplication $2 \tau_{\mathrm{s}} \mathrm{f}_{\mathrm{s}}\left(2 \tau_{\mathrm{s}}=4.50-5.50 \mathrm{~ms}, \mathrm{f}_{\mathrm{s}}=1560 \mathrm{~Hz}\right)$ is 6.8-8.3. Thus, the dynamic responses of LWPSPS in the present case can also be seen as quasi-static. Normally, this criterion is absolutely true as a matter of fact that the slamming duration time is about $0.02 \mathrm{~s}-0.1 \mathrm{~s}$ in practical case [19], which is much longer than that of the present investigation.

While the dynamic inertial effect cannot be ignored, the calculation of dynamic deflection in linear elastic range under uniform impact pressure is given by following equation [36]:

$$
K(t)=\frac{w_{d}(t)}{w_{s}}=\frac{\omega}{p_{\max }} \int_{0}^{t} p(\tau) \sin \omega(t-\tau) d \tau
$$

where $\mathrm{K}(\mathrm{t})$ is the dynamic inertial effect factor function, $\omega$ is the first circular frequency of structure, $\mathrm{p}_{\max }$ is the peak pressure value of impact, $p(\tau)$ is the formula of impact loading, $w_{d}(t)$ is the load-deflection function and $\mathrm{w}_{\mathrm{s}}$ is the static deflection of structure under uniform maximum pressure $\mathrm{p}_{\max }$. The maximum value of $\mathrm{K}(\mathrm{t})$ at $\mathrm{t}=\mathrm{t}_{0}$ is commonly considered in the practical case, which satisfies the following conditions: 


$$
\frac{\mathrm{dK}(\mathrm{t})}{\mathrm{dt}}=\left.0\right|_{\mathrm{t}=\mathrm{t}_{0}}, \frac{\mathrm{d}^{2} \mathrm{~K}(\mathrm{t})}{\mathrm{dt}^{2}}<\left.0\right|_{\mathrm{t}=\mathrm{t}_{0}}
$$

In this study, the maximum value of $\mathrm{K}(\mathrm{t})$ (Here it is defined as $\eta_{\mathrm{sd}}$ ) can be easily calculated for monolithic plate based on Eqs. (7)-(10) and Eqs. (15)-(16). The value of $\mathrm{K}$ is only associated with the fundamental circular frequency $\omega$ and the impact duration time $2 \tau_{\mathrm{s}}$ in Eq. (15). If the fundamental frequency is obtained in the previous section 4.1, the maximum value of $\mathrm{K}(\mathrm{t})$ for LWPSPS (Here it is defined as $\eta_{\mathrm{sd}}{ }^{\mathrm{s}}$ ) can be calculated from Eqs. (15)-(16).

In the present investigation, $\eta_{\text {sd }}$ (for monolithic plate) is equal to $1.20-1.25$. For LWPSPS, $\eta_{\mathrm{sd}}{ }^{\mathrm{s}}$ is equal to $1.05-1.10$. Compared with computation results, the values for $\eta_{\mathrm{sd}}$ and $\eta_{\mathrm{sd}}{ }^{\mathrm{s}}$ are both verified reasonable. Therefore, the values of $\eta_{\mathrm{sd}}$ $(1.20 \sim 1.25)$ and $\eta_{\mathrm{sd}}{ }^{\mathrm{s}}(1.05 \sim 1.10)$ indicate that the dynamic inertial effects is not remarkable during the water impact process in these cases.

Considering the added mass of the first vibration modal of structure for a v-shaped ship section, a similar definition given by Stenius et al. [6, 10, 37] is defined as follow:

$$
\mathrm{R}=\mathrm{T}_{\mathrm{LP}} / \mathrm{T}_{\mathrm{NP}}
$$

where $T_{L P}$ is the loading period based on the Wagner theory, and $\mathrm{T}_{\mathrm{NP}}$ is the first wet natural period of vibration. It is concluded that the hydroelastic effects are negligible and the response can be set as quasi-static for $\mathrm{R}>4[6,10,37]$.

Obviously, the first wet natural period of vibration $T_{\mathrm{NP}}$ is longer than the first dry natural period of vibration $T_{\mathrm{NPB}}$. Though a detailed hydroelastic analysis of two-dimensional $\mathrm{v}$-shaped transverse section was conducted in $[6,10,37]$, the hydroelastic problem of a flat panel with zero wedge deadrise angle are neglected in previous investigations.

The indicator of hydroelastic effect introduced by Bereznitski [8] and the inertia effect indicator introduced by Jones [27] are both based on the dry natural period of vibration. However, the added water mass is not considered in their analysis. Pointed out by Stenius et al. [6, 10,37], hydroelastic effects incorporate both dynamic inertial effect and added mass effect. Thus, the added water mass should be considered in the evaluation of hydroelastic effects.

For a rectangular clamped monolithic plate with one face contacted with water, the added water mass coefficient is defined as $f_{A} / f$ according to Ref. [30]:

$$
\frac{\mathrm{f}_{\mathrm{A}}}{\mathrm{f}} \cong \frac{1}{\sqrt{1+\zeta \frac{\mathrm{a}}{\gamma_{\mathrm{s}} \mathrm{t}}}}
$$

where $\mathrm{f}$ is the first dry natural frequency of vibration, $\mathrm{f}_{\mathrm{A}}$ is the first wet natural frequency of vibration, $t$ is the thickness of this rectangular monolithic panel, $\gamma_{\mathrm{s}}$ is the specific gravity of steel (here $\gamma_{\mathrm{s}}=7.85$ ), $\mathrm{a}$ is the length of this monolithic plate and $\zeta$ is the constant based on the length-width ratio of $\mathrm{a} / \mathrm{b}$. In the present case, the ratio of $a / b$ is equal to 2.2 and the value $f_{A} / f$ is equal to 1.34. According to this observation, the first wet natural frequency of vibration $\mathrm{f}_{\mathrm{A}}$ is equal to $699 \mathrm{~Hz}$ which is consistent with the result $(677 \mathrm{~Hz})$ obtained by FSI vibration analysis in ANSYS by using acoustic fluid element Fluid30 [38].

As the FSI occurs, the calculation of wet natural frequencies of LWPSPS (here it is defined as $\mathrm{f}_{\mathrm{A}}{ }^{\mathrm{s}}$ ) is greatly complicated. Up to now, no study analyzed the FSI vibration characteristic of LWPSPS. Thus, the acoustic-solid coupling method in commercial code ANSYS is adopted to calculate the wet natural frequencies of LWPSPS. The fluid is also modeled as non-viscous acoustic fluid element Fluid30, and Lagrange elements (shell 63 and beam 181) are adopted for solid parts (face sheets and core trusses); where the sum of all elements is nearly 80,000 . When the added water mass effect is taken into account, the first wet natural frequency of LWPSPS is $1034 \mathrm{~Hz}$ for Case 1 - Case 6 , which is about $2 / 3$ of the first dry natural frequency $(1553 \mathrm{~Hz})$.

Once the first wet natural frequency of LWPSPS is obtained, the hydroelastic indicator of R can be calculated. By applying Eq. (14), the value of hydroelastic indicator R for LWPSPS (C1-C6) is $4.653-5.687\left(2 \tau_{\mathrm{s}}=4.50-5.50 \mathrm{~ms}\right)$. In Ref. [6, $10,37]$, Stenius et al. concluded that the hydroelastic effects are negligible when $\mathrm{R}>4$. Thus, one could give a definitive conclusion that the hydroelastic effect of LWPSPS is not significant based on this criteria.

This conclusion can be validated from 3D FEM FSI simulation results (3D-FEM-FSI), 3D FEM dynamics simulation results (the FSI effects are not considered, 3DFEM-Dynamic) and 3D FEM quasi-static simulation results (3D-FEM-Static) in Fig. 8. The comparison of these analyses shows that the results of 3D-FEM-FSI and 3D-FEM-Dynamic are very close, which means the hydroelastic effect is not significant. As shown in Fig. 8, due to the neglect of inertial effect, the quasi-static results are slightly lower than the results of dynamic calculation.

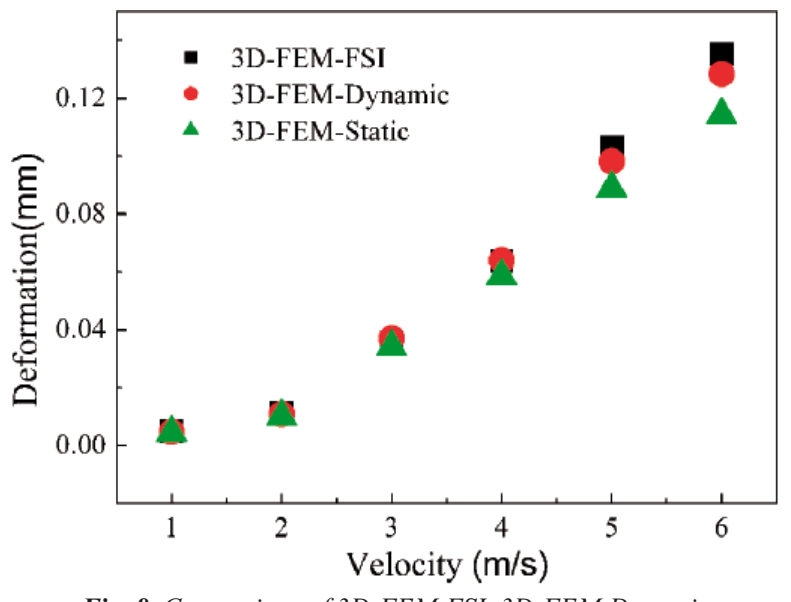

Fig. 8. Comparison of 3D-FEM-FSI, 3D-FEM-Dynamic and $3 D$-FEM-Static Results

4.3. Engineering approach of maximum deformation for LWPSPS

Next, the analytical investigations are performed to study the deformation characteristics of LWPSPS. As shown in Fig. 9, the inflection points exist at adjacent lattice core cells. The total deformation field of LWPSPS can be divided into two components:

1) The global bending deformation field of LWPSPS $\left(\mathrm{w}_{\max , \mathrm{T}}\right)$.

2) The local bending deformation field of each cell $\left(\mathrm{w}_{\max , \mathrm{L}}\right)$.

Based on this deformation field assumption, a mathematical model to describe the total maximum deformation field is presented as follow:

$$
\mathrm{W}_{\max }=\mathrm{W}_{\max , \mathrm{T}}+\mathrm{W}_{\max , \mathrm{L}}
$$

- Calculation of the global bending deformation $\mathrm{w}_{\max , \mathrm{T}}$.

The global linear elastic maximum deformation $\mathrm{w}_{\max , \mathrm{T}}$ of sandwich plate with clamped boundary condition under static uniform pressure is given by [35]: 


$$
\begin{aligned}
& \mathrm{W}_{\max , \mathrm{T}}=\frac{4 \mathrm{p}_{\max } \mathrm{a}^{4}}{\pi^{4} \mathrm{D}_{1}} \sum_{\mathrm{m}=1,3 \ldots}^{\infty} \frac{(-1)^{\frac{(\mathrm{m}-1)}{2}}}{\mathrm{~m}^{5}} . \\
& \cdot\left[\left(1-\frac{\alpha_{\mathrm{m}} \mathrm{th}\left(\alpha_{\mathrm{m}}\right)+2}{2 \operatorname{ch}\left(\alpha_{\mathrm{m}}\right)}\right)-\delta_{\mathrm{m}}\left(1-\frac{1}{\operatorname{ch}\left(\alpha_{\mathrm{m}}\right)}\right)\right]+ \\
& +\sum_{m=1,3 \ldots}^{\infty}(-1)^{\frac{(m-1)}{2}}\left(\frac{\alpha_{m} \operatorname{th}\left(\alpha_{m}\right)}{2 m^{2} \pi^{2} \operatorname{ch}\left(\alpha_{m}\right)} \frac{a^{2}}{D_{1}} H_{m}\right)+ \\
& +\sum_{n=1,3 \ldots}^{\infty}(-1)^{\frac{(n-1)}{2}}\left(\frac{\alpha_{n} \operatorname{th}\left(\alpha_{n}\right)}{2 n^{2} \pi^{2} \operatorname{ch}\left(\alpha_{n}\right)} \frac{a^{2}}{\alpha^{2} D_{1}} G_{n}\right) \\
& \alpha_{m}-\left(\alpha_{m} \text { th }\left(\alpha_{m}\right)-1\right) \operatorname{th}\left(\alpha_{m}\right)+ \\
& +2 \delta_{\mathrm{m}}\left(\operatorname{th}\left(\alpha_{\mathrm{m}}\right)-\frac{\mathrm{m} \pi}{\eta_{\mathrm{m}}} \operatorname{th}\left(\alpha_{\mathrm{m}}\right)\right) \mathrm{H}_{\mathrm{m}}+\sum_{\mathrm{n}=3}^{\infty} \frac{8 \mathrm{~nm}^{2}}{\alpha} . \\
& \cdot\left[\frac{1}{\alpha^{3} \pi\left(\frac{m^{2}}{\alpha^{2}}+n^{2}\right)^{2}}-\frac{\delta_{m}}{m^{2} \pi}\left(\frac{1 / \alpha}{\frac{m^{2}}{\alpha^{2}}+n^{2}}-\frac{\pi^{2}}{\left.\alpha \eta_{n}^{2}+\frac{m^{2} \pi^{2}}{\alpha}\right)}\right] G_{n}+\right. \\
& +\frac{1}{\mathrm{~m}^{3}}\left[\left(\alpha_{\mathrm{m}} \operatorname{th}\left(\alpha_{m}\right)+1\right) \operatorname{th}\left(\alpha_{\mathrm{m}}\right)-\alpha_{\mathrm{m}}\right] \mathrm{p}_{\max }=0 \\
& \alpha_{n}-\left(\alpha_{n} \operatorname{th}\left(\alpha_{n}\right)-1\right) \operatorname{th}\left(\alpha_{n}\right)+ \\
& +2 \delta_{\mathrm{n}}\left(\operatorname{th}\left(\alpha_{\mathrm{n}}\right)-\frac{\mathrm{n} \pi}{\eta_{\mathrm{n}}} \operatorname{th}\left(\alpha_{\mathrm{n}}\right)\right) \mathrm{G}_{\mathrm{n}}+\sum_{\mathrm{n}=3}^{\infty} \frac{8 \mathrm{mn}^{2}}{\alpha} . \\
& \cdot\left[\frac{1}{\pi\left(\frac{m^{2}}{\alpha^{2}}+n^{2}\right)^{2}}-\frac{\delta_{m}}{n^{2} \pi}\left(\frac{1 / \alpha}{\frac{m^{2}}{\alpha^{2}}+n^{2}}-\frac{\pi^{2}}{\frac{\eta_{m}^{2}}{\alpha^{2}}+n^{2} \pi^{2}}\right)\right] H_{m}+ \\
& +\frac{1}{\alpha^{2} n^{3}}\left[\left(\alpha_{n} \text { th }\left(\alpha_{n}\right)+1\right) \operatorname{th}\left(\alpha_{n}\right)-\alpha_{n}\right] p_{\max }=0 \\
& \alpha_{\mathrm{m}}=\frac{\mathrm{m} \pi \mathrm{b}}{2 \mathrm{a}}, \eta_{\mathrm{m}}=\left[\mathrm{m}^{2} \pi^{2}+\frac{2}{\delta_{\mathrm{a}}(1-v)}\right]^{1 / 2}, \\
& \delta_{\mathrm{a}}=\frac{\mathrm{D}_{1}}{\mathrm{C}_{\mathrm{G}} \mathrm{a}^{2}}, \delta_{\mathrm{m}}=\mathrm{m}^{2} \pi^{2} \delta_{\mathrm{a}} \\
& \alpha_{n}=\frac{n \pi a}{2 b}, \eta_{n}=\left[n^{2} \pi^{2}+\frac{2}{\delta_{b}(1-v)}\right]^{1 / 2}, \\
& \delta_{\mathrm{b}}=\frac{\mathrm{D}_{1}}{\mathrm{C}_{\mathrm{G}} \mathrm{b}^{2}}, \quad \delta_{\mathrm{n}}=\mathrm{n}^{2} \pi^{2} \delta_{\mathrm{b}}
\end{aligned}
$$

- Calculation of the local bending deformation field of each

where $\mathrm{C}_{\mathrm{G}}$ is the equivalent shear stiffness of lattice core and $\mathrm{p}_{\max }$ is the maximum value of average FSI pressure, the other nomenclatures have the same meanings as mentioned in the cell $\mathrm{w}_{\text {max }, \mathrm{L}}$.

The confirmation of boundary condition is a key step to analyze the local deformation field of each cell. Here, three boundary condition assumptions of lattice cell are compared as follows:

1. Cylindrical bending with built-in edges (Analytical-C, see Fig. 10a)[39]

$$
\mathrm{W}_{\max , \mathrm{L}}=\frac{\mathrm{p}_{\max } \mathrm{d}_{\mathrm{c}}^{4}}{384 \mathrm{D}_{1}}
$$

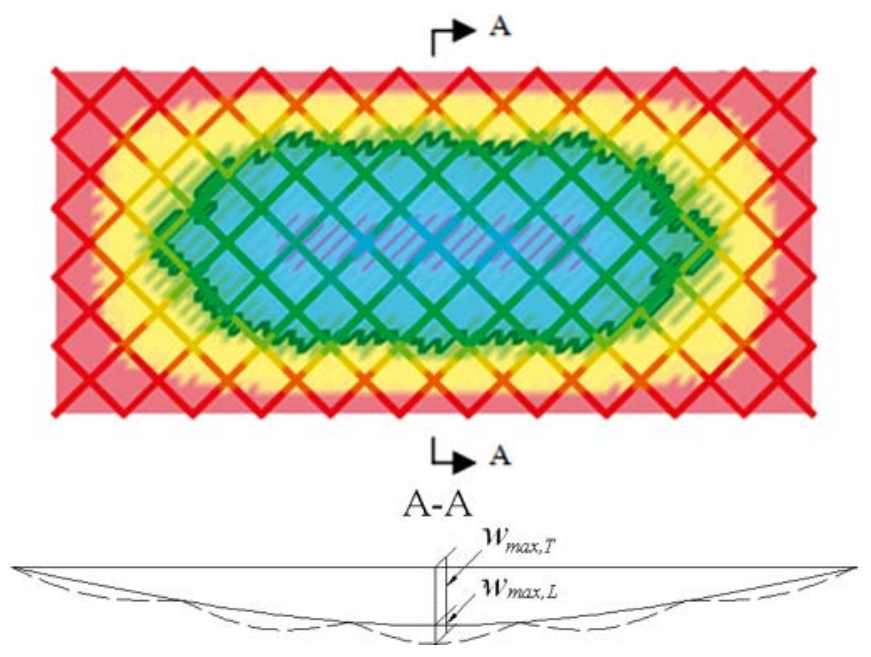

previous section. Firstly, the bending and shear stiffness of lattice core $\mathrm{D}_{1}$ and $\mathrm{C}_{\mathrm{G}}$ are calculated from Eqs. (12) - (13). and Eq. (20c). If all the parameters in Eqs. (20b) - (20e) are observed, the maximum static deformation can be easily solved from Eq. (20a)

2. Cylindrical bending with simply supported edges (Analytical-S, see Fig. 10b) [39]

$$
\mathrm{W}_{\max , \mathrm{L}}=\frac{5 \mathrm{p}_{\max } \mathrm{d}_{\mathrm{c}}^{4}}{384 \mathrm{D}_{1}}
$$

3. Bending of each lattice cell supported by rows of equidistant trusses (Analytical-T, see Fig. 10c) [39]

$$
\mathrm{W}_{\max , \mathrm{L}}=0.005507 \frac{\mathrm{p}_{\max } \mathrm{d}_{\mathrm{c}}^{4}}{\mathrm{D}_{\mathrm{l}}}
$$

Where $\mathrm{w}_{\text {max }, 1}$ is the local maximum deformation, $\mathrm{p}_{\max }$ is the maximum value of water impact pressure loading on central cells, $d_{c}$ is the width of cell (see Fig. 1) and $D_{1}$ is the flexural rigidity of cell face sheet defined as:

$$
\mathrm{D}_{1}=\frac{\mathrm{Et}_{\mathrm{b}}^{3}}{12\left(1-v^{2}\right)}
$$

If the inertial effect during water impact loading process is significant $\left(2 \tau_{\mathrm{s}} \mathrm{f}_{\mathrm{s}} \sim 1.0\right)$, the total static deformation $\mathrm{W}_{\max , \mathrm{T}}$ of LWPSPS must be multiplied the dynamic load inertial coefficient $\eta_{\mathrm{sd}} \mathrm{s}$. The value of $\eta_{\mathrm{sd}} \mathrm{s}$ is equal to $1.05-1.10$ for case 1 - case 6 from Eq. (16) and Eq. (17). Here, the value 1.10 of $\eta_{\mathrm{sd}} \mathrm{s}$ is adopted in the following investigation.

Compared with the 3D-FEM FSI simulation, the maximum deformations $\mathrm{w}_{\max }$ of LWPSPS under different water impact velocity for the three assumptions (Analytical-C, Analytical-S and Analytical-T) are illustrated in Fig. 11. It is clear that the analytical deflections match well with computed results by 


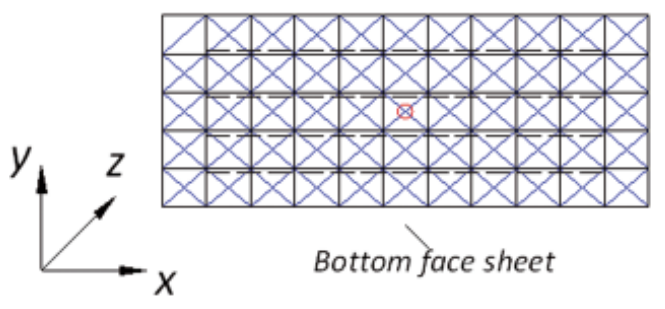

a) Analytical-C

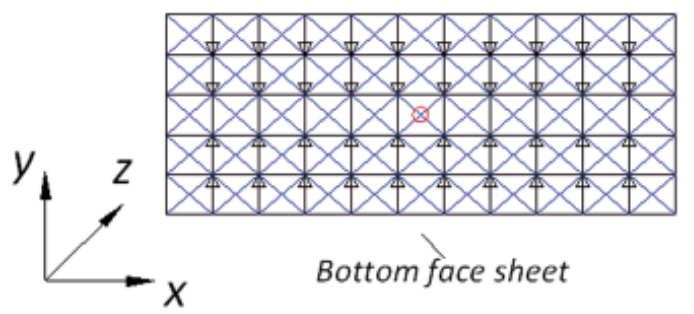

b) Analytical-S

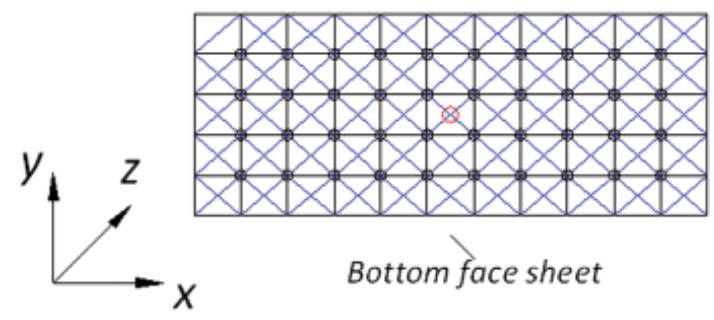

c) Analytical-T

Fig. 10. Three local cell deformation field assumptions of LWPSPS

adopting the Analytical-S assumption. The results show that the maximum percentage difference $\left(100 \% \times\left(\mathrm{W}^{\text {sim }}-\mathrm{W}^{\mathrm{anl}}\right) / \mathrm{W}^{\mathrm{sim}}\right)$ between this engineering approach (Wanl) and the FSI simulation results $\left(\mathrm{W}^{\text {sim }}\right)$ is less than $9 \%$ (impact velocity $\mathrm{v}=3-6 \mathrm{~m} / \mathrm{s}$ ). Furthermore, the results based on Analytical-T assumption can give a better estimation in the low velocity range (impact velocity $\mathrm{v}=1-2 \mathrm{~m} / \mathrm{s}$ ). The maximum difference between the simulation and the approximate method is less than $3 \%$. As shown in Fig. 11, the results based on Analytical-C assumption for LWPSPS are unacceptable.

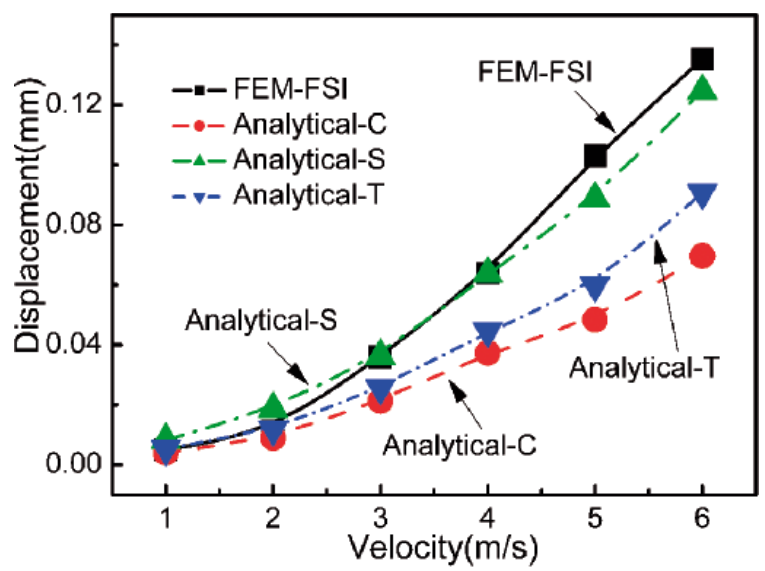

Fig. 11. Comparison of the maximum deformation of LWPSPS by using approximate method and FSI simulation

\section{PARAMETRIC STUDY}

In this section, the effects of design parameters of $t_{b}, t_{f}$, $\mathrm{H}_{\mathrm{c}}, \mathrm{t}_{\mathrm{c}} \times \mathrm{t}_{\mathrm{c}}$ on water impact pressure and maximum deflection of LWPSPS are examined by numerical simulation and engineering prediction.

\section{Effects of thickness of face sheets $t_{b}$ and $t_{f}(C 7-C 14)$}

To investigate the effects of thickness of face sheet on water impact loading pressure, LWPSPS with four different bottom face sheet thicknesses (C7 - C10) and four different top face sheet thicknesses $(\mathrm{C} 11-\mathrm{C} 14)$ are considered. The material properties, plate geometry, water impact velocity and boundary conditions are the same as those that adopted in the previous study for C1 - C6.

With respect to the fundamental case $\mathrm{C} 1$, the variation in thickness of bottom face sheet $t_{b}$ leads to the significant shifts of water impact loading pressure and maximum deflection, as shown in Fig. 12 and Fig. 13. However, the influence of variation in thickness of top faces $t_{f}$ is insignificant. With the increase in thickness of $t_{b}$ (the contact water face sheet "hardens"), the FSI peak pressure of central point increases, as illustrated in Fig. 12. On the contrary, the average FSI peak pressure of contacted water face sheet has a minimum when $\mathrm{t}_{\mathrm{b}}$ is nearly equal to $4.5 \mathrm{~mm}$.

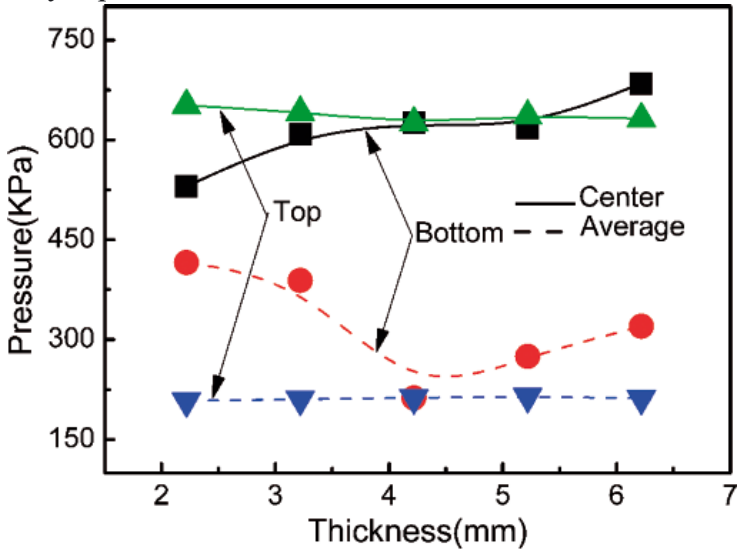

Fig. 12. Peak water impact pressure magnitudes at central point and average FSI area with different face sheet thickness: top and bottom

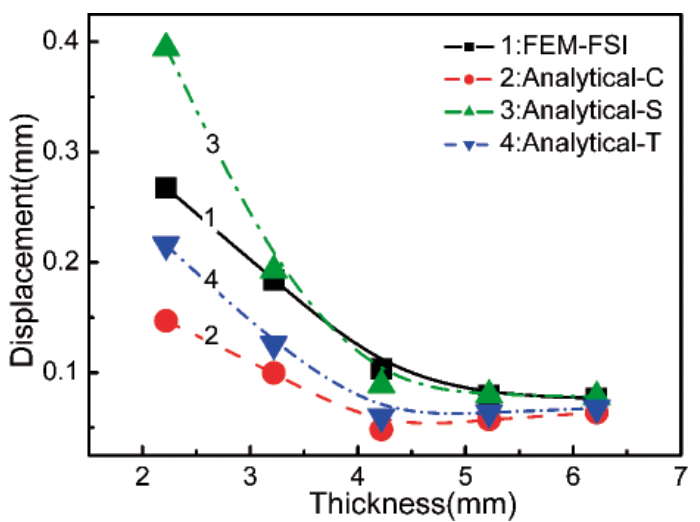

Fig. 13. Maximum deformations of LWPSPS with different bottom face sheet thickness predicted by analytical method and FEM 
It can be seen clearly from Fig. 13 that, with the thickness of bottom face sheet increases, the deformation curves demonstrate a progressive decrease when $\mathrm{t}_{\mathrm{b}}<4.5 \mathrm{~mm}$. Contrarily, when $\mathrm{t}_{\mathrm{b}}>4.5 \mathrm{~mm}$, a slowly increasing trend of deformation curve is observed. In an interpreting way, when $\mathrm{t}_{\mathrm{b}}>4.5 \mathrm{~mm}$, though the flexural rigidity of LWPSPS increase slowly, both the central pressure and the average pressure increase faster, as shown in Fig. 12.

With no remarkable change of water impact pressure, the maximum deformation magnitude of LWPSPS is smaller when $\mathrm{t}_{\mathrm{f}}$ becomes thicker (Fig. 14). The approximate method also gives good estimations here under the Analytical-S assumption, and the error is less than $10 \%$ in most of the cases. With very few exceptions $\left(\mathrm{t}_{\mathrm{f}}\right.$ or $\left.\mathrm{t}_{\mathrm{b}}=2.219 \mathrm{~mm}\right)$, the precision of this analytical prediction is high enough. As a possible factor, the Analytical-S assumption cannot reflect the true boundary condition of local lattice cell when the face sheet is relatively thin.

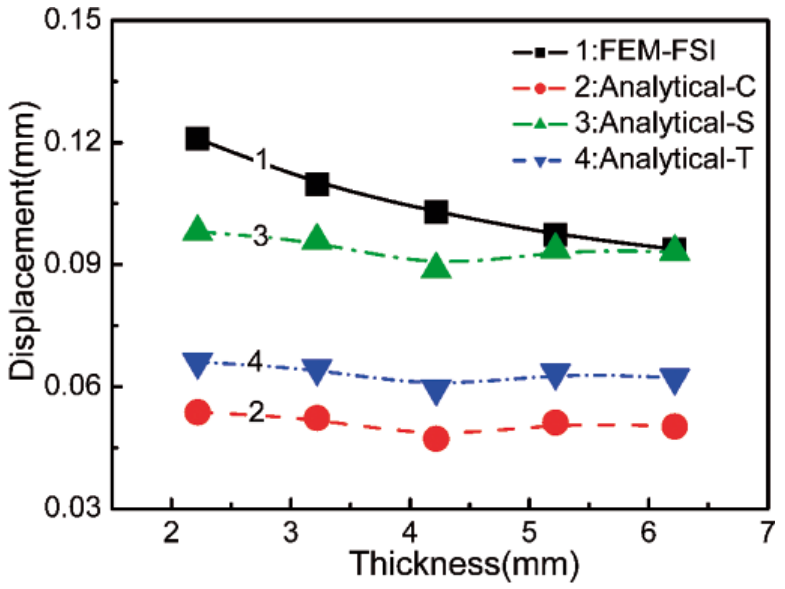

Fig. 14. Maximum deformations of LWPSPS with different top face sheet thickness predicted by analytical method and FEM

\section{Effects of core thickness of LWPSPS $\mathrm{H}_{c}(\mathrm{C15}-\mathrm{C18})$}

Next, the influence of core thickness on the water impact pressure and maximum deflection of LWPSPS is considered (C15 - C18, see Table 1). The peak pressure magnitude versus core thickness for C15 - C18 under the same water impact velocity $5 \mathrm{~m} / \mathrm{s}$ are demonstrated in Fig. 15 . Along with the increasing thickness of core, the peak pressure value moves to a lower magnitude. As illustrated in Fig. 15, the slope of decreasing curve changes slowly for central pressure when $\mathrm{H}_{\mathrm{c}}$ is in the range of $1.825-2.825 \mathrm{~cm}$. But the slope of central pressure curve drops dramatically in the range of $\mathrm{H}_{\mathrm{c}}=2.825-5.825 \mathrm{~cm}$. Moreover, a slight decrease of average FSI peak pressure magnitude with a thicker core is observed.

To quantify the effects of core thickness of LWPSPS on the structural response, the predicted deflections versus core thickness are plotted for these four cases with three different local boundary condition assumptions, as shown in Fig. 16. As the thickness of core increases, it is shown that the deformation of LWPSPS decreases rapidly in the range of $\mathrm{H}_{c}=1.825$ $4.825 \mathrm{~cm}$. This is because of the decrease of FSI pressure and the increase of bending rigidity of LWPSPS with thicker core. The best prediction of maximum deformation of LWPSPS is also obtained under the Analytical-S assumption. When $\mathrm{H}_{\mathrm{c}}>2.5 \mathrm{~cm}$, the engineering approach results are consistent well with those obtained from numerical calculation. Also with very few exceptions (when $\mathrm{H}_{\mathrm{c}}<2.5 \mathrm{~cm}$ ), the discrepancy between the numerical results and the analytical solutions displays in
Fig. 16. Compared with FEM result, the error of the prediction is about $25 \%$.

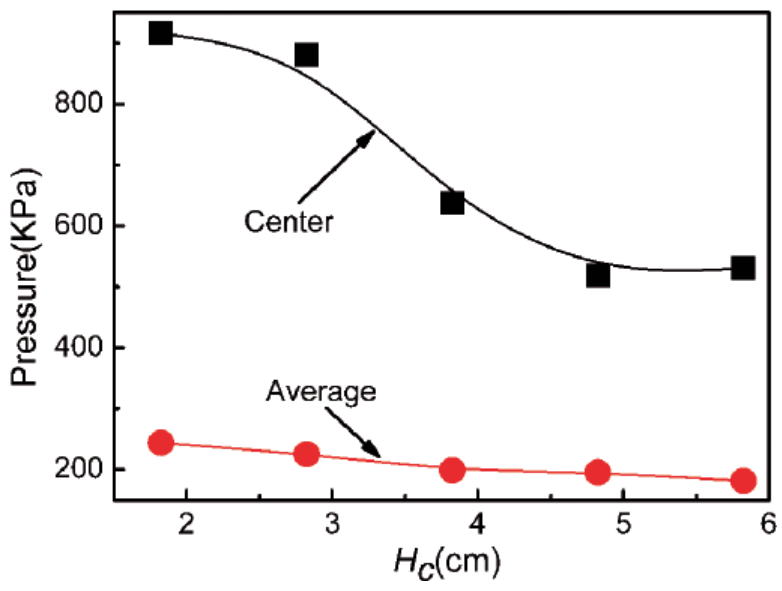

Fig. 15. Peak water impact pressure magnitudes at central point and average FSI area with different core thicknesses

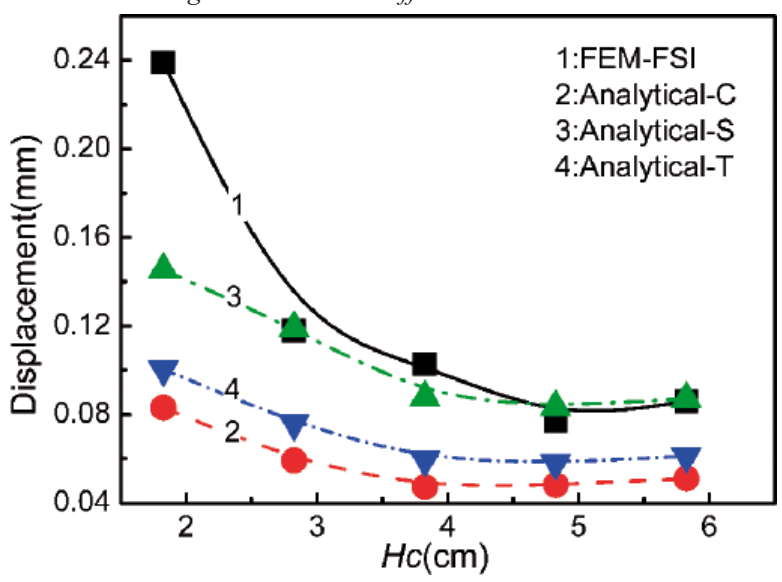

Fig. 16. Maximum deformations of LWPSPS with different core thicknesses predicted by analytical method and FEM

\section{Effects of cross section area $t_{c} \times t_{c}(C 19-C 22)$}

Finally, the influence of the section area of lattice column as an indicator of relative density is discussed. According to the calculation results, nearly 2 times increasing of relative density of lattice core (from 4.83 to $9.47 \%$ ) results in $10 \%$ decrement of FSI pressure located in the central point and $10 \%$ increment of the average FSI pressure.

As demonstrated previously, the contacted water face sheet and core thickness both have significant effects on the dynamic response behavior of LWPSPS. But it is shown that the change of relative density has a slight effect on the dynamic response behavior. In contrast, in the evaluation of the energy absorption characteristic of LWPSPS under intense impact loading such as UNDEX (underwater explosion) or AIREX (air explosion), the relatively density of lattice core plays a pivotal role on the dynamic mechanical properties of lattice materials [17-18]. However, unlike with the plastic collapse under these intense impact loads (UNDEX or AIREX), the serious failure modes (like the plastic dynamic buckling) would not occur under the practical water impact loading (here, impact velocity $\mathrm{v}=5 \mathrm{~m} / \mathrm{s}$ ) only if the relative density is extremely low.

The maximum deformations of C19 - C22 are also predicted by numerical simulation and analytical method. With no remarkable change of the water impact pressure, the corresponding results demonstrate that the maximum deformation decreases slowly (about $20 \%$ ). 


\section{CONCLUSIONS}

The hydroelastic characteristics for light weight pyramidal sandwich plate structures (LWPSPS) under water impact by using 3D simulation are studied. A theoretical hydroelasticity assessment model for LWPSPS and a new engineering approach method to predict the maximum deformation of LWPSPS under water impact load are developed.

In numerical analysis, an arbitrary Lagrangian and Eulerian algorithm (ALE) in the nonlinear finite element code LS-DYNA is used to simulate the fluid-solid interaction phenomenon between structure hull and fluid medium. The equivalent core model and the approximation method are adopted to calculate the fundamental bending vibration frequencies of LWPSPS. Furthermore, based on the first fundamental modal frequency, the hydroelastic characteristic is discussed in detail by introducing a non-dimensional criterion $2 \tau_{\mathrm{s}} \mathrm{f}_{\mathrm{s}}$. By dividing the real displacement field of LWPSPS into global displacement field and local displacement field, the real maximum deformation solutions are obtained. Compared with 3D FEM results, the results of the engineering calculation method presented in this analysis are obtained with good accuracy. At last, the influences of key design parameters of LWPSPS on dynamic behavior are quantified, including the face sheet thickness, the thickness of lattice core and the relative density of LWPSPS core.

The following conclusions from the viewpoint of hydroelastic characteristics of LWPSPS can be drawn:

1) In the form of water impact velocity, the performance of water impact pressure for LWPSPS is close to two parameters parabolic mathematical expression. Compared with the monolithic plate, in medium-high water impact velocity range $(2 \mathrm{~m} / \mathrm{s}-6 \mathrm{~m} / \mathrm{s})$, the advantage of deceasing water impact pressure peak for LWPSPS is significant. A notable phenomenon called "local air cushion" exists during the initial water impact process of LWPSPS caused by the cell local deformation, which has significant effects on the dynamic characteristic of LWPSPS.

2) The hydroelastic effect of LWPSPS is not significant in the present study because the non-dimensional criteria $2 \tau_{\mathrm{s}} \mathrm{f}_{\mathrm{s}}>4$, which means the duration time of water impact pressure loading is much longer than the first wet natural period of vibration.

3) Results from the proposed engineering analytical model are in good agreement with those from finite element predictions for LWPSPS. All the geometric parameters are included and the local structural displacement is captured in this model. The predictions based on this method show that, compared with the other two local deformation field assumptions (cylindrical bending with simply supported edges and cylindrical bending with built-in edges), the local cylindrical bending assumption with simply supported edges each row lattice core is more realistic to reflect the true boundary condition in most cases.

4) In the parametric study of LWPSPS, it is found that the thinning of contacted water face sheet reduces the central water impact loading pressure, while the average FSI water impact loading pressure has a local minimum value at a certain thickness. Additionally, along with the increasing of core thickness, the peak pressure moves to a lower magnitude. Another key design parameter-the relative density of lattice core, has no significant effect on the FSI pressure and maximum deflection when the relative density of core is doubled.

\section{Acknowledgements}

The authors are pleased to acknowledge the support of the National Natural Science Foundation of P.R. China (Contract No. 51079058) and the Research Award Program for Outstanding Doctor Thesis of Huazhong University of Science and Technology (Contract No. 0109140921).

\section{BIBLIOGRAPHY}

1. Faltinsen O.M.: Hydrodynamics of High-Speed Marine Vehicles. Cambridge, UK: Cambridge University Press, 2005.

2. DNV:. Rules for Classification of High Speed, Light Craft and Naval Surface Craft. 2012.

3. Karman V.T.: The impact on sea plane floats during loading. NACA-TN-321, 1929.

4. Wagner H.: Loading of seaplane. NACA-TN-622, 1932.

5. Chuang S.L.: Investigation of impact of rigid and elastic bodies with water. NSRDC-TR-3248, 1970.

6. Stenius I., Rosen A., Battley M., et al.: Hydroelastic Effects in Slamming Loaded Panels. In: 11th. International Conference on Fast Sea Transportation (FAST 2011), Honolulu, Hawaii, USA, 26-29 September 2011. p. 644-652.

7. Faltinsen O.M.: Hydroelastic slamming. Journal of Marine Science and Technology 2000; 5(2):49-65.

8. Berezniski A.: Slamming: the role of hydroelasticity. International Shipbuilding Progress 2001;48(4):333-351.

9. Hirdaris S.E., Temarel P.: Hydroelasticity of ships: Recent advances and future trends. Proceedings of the Institution of Mechanical Engineers, Part M: Journal of Engineering for the Maritime Environment 2009;223(3):305-330.

10.Stenius I., Rosen A., Kuttenkeuler J.: Hydroelastic interaction in panel-water impacts of high-speed craft. Ocean Engineering 2011;38(2-3):371-381.

11. Metschkow B.: Sandwich panels in shipbuilding. Polish Maritime Research 2006 special issue 1:5-8.

12.Kozak J.: Selected problems on application of steel sandwich panels to marine structures. Polish Maritime Research 2009;16(4):9-15.

13.Qin Z., Batra R.C.: Local slamming impact of sandwich composite hulls. International Journal of Solid and Structures 2009;46(10):2011-2035.

14.Baral N., Cartie D.R., Partridge I.K., et al.: Improved impact performance of marine sandwich panels using through-thickness reinforcement: experimental results. Composite Part B: Engineering 2010;41(2):117-123.

15.Pancirolia R., Abrateb S., Minaka G., et al.: Hydroelasticity in water-entry problems: Comparison between experimental and SPH results. Composite Structures 2012;94(2): 532-539.

16.Vasiliev V.V., Barynin V.A.: Anisogrid composite lattice structures-Development and aerospace applications. Composite Structures 2012;94(3):1117-1127.

17.McShane G.J., Deshpande V.S. and Fleck N.A.: The underwater blast resistance of metallic sandwich beams with prismatic lattice cores. Journal of Applied Mechanics 2007;74(2): 352364

18.Zhu F., Lu G.X., Ruan D., et al.: Plastic Deformation, Failure and Energy Absorption of Sandwich Structures with Metallic Cellular Cores. International Journal of Protective Structures 2010;1(4):507-541.

19.Greenspon J.E.: Sea tests of the U.S.C.G.C. Unimak (Part3). DTMB-TR-978,1956.

20.Olovsson L., Souli M.: LS-DYNA Advanced Course in ALE and Fluid-Structure Coupling. Class Notes, Livermore Software Technology Corporation, Livermore, CA, 2000.

21.Aquelet N., Souli M., Olovsson L.: Euler-Lagrange coupling with damping effects-Application to slamming problems. Computer Methods in Applied Mechanics and Engineering 2006; 195(1-3):110-132. 
22.Stenius I., Rosen A., Kuttenkeuler J.: Explicit FE-modeling of fluid-structure interaction in hull-water impacts. International Shipbuilding Progress 2006;53(2):103-121.

23.Jones N.: Structural Impact. Cambridge, UK: Cambridge University Press, 1989.

24.Symonds P.S.: Survey of methods of analysis for plastic deformation of structures under dynamic loading. Brown University, Division of Engineering Report, 1967.

25.Yuzuru F.: On the impulsive of circular plate falling upon water surface. Journal of Zosen Kiokai 1954;94:105-110. (In Japanese)

26.McKirgan J.: Characterization of aluminum 6061-T6 tube for high-rate loading applications. Naval Surface Warfare Center (NSWC) Carderock Division Technical Report, 2004.

27.Jones N.: Slamming damage. Journal of Ship Research 1973;17(2):80-86.

28. Wierzbicki T., Chryssostomidis C., Wiernicki C.: Rupture analysis of ship plating due to hydrodynamic wave impact. Ship Structure Symposium'84, Arlington, VA, 15-16 October 1984. p.237-256.

29.Nagai T.: Elastic response of high tensile steel plates developed by impact on water surface. Bulletin of Society of Japan Naval Architecture and Ocean Engineering 1966; 120:175-184. (In Japanese)

30.Szymanski Y.A.: Ship Structural Mechanics Guide (Volume II). Moscow, RUS: National Technology Press, 1959. (Шиманский Ю А. Корабль структурных руководства механика (том II). Москва, Россия: Национальный технологии Пресс, 1959.). (In Russian)

31.Liu T., Deng Z.C., Lu T.J.: Design optimization of truss-cored sandwich with homogenization. International Journal of Solid and Structures 2006;43(25-26):7891-7918.
32.Wadley H.N.G.: Multifunctional periodic cellular metals. Philosophical Transactions of the Royal Society A 2006;364(1838): 31-68.

33.Edward W.K.: Flexure of structural sandwich construction. Forest Productions Laboratory Report NO.1829, 1951.

34.Bolotin B.B.: Calculation of strength. 1960, 6(6), Mashgiz. (Болотин В В. Расчёт на прочность, вьі(6), Машгиз, 1960). (In Russian)

35.Institute of Mechanics, Chinese Academy of Sciences. Bending, Vibration and Stability of Sandwich Plates and Shells. Beijing, CHN: Science Press, 1977. (In Chinese)

36.Biggs J.B.: Introduction to Structural Dynamics. New York, US: McGraw-Hill, 1964.

37.Stenius I., Rosen A., Kuttenkeuler J.: Explicit FE-modeling of hydroelasticity in panel-water impacts. International Shipbuilding Progress 2007;53(2-3):111-127.

38.ANSYS Inc. ANSYS Theory Manual (Version 5.0). 2002.

39. Timoshenko S., Woinowsky-Krieger S.: Theory of plates and shells. New York, US: McGraw-Hill, 1959.

\section{CONTACT WITH THE AUTHORS}

Hao Wang, Dr.,

Fei Zhao, master graduate student,

Yuan-Sheng Cheng*), Dr., Professor, Jun Liu, Dr., Lecturer

Yuan Tian, master graduate student, School of Naval Architecture and Ocean Engineering, Huazhong University of Science and Technology, Wuhan 430074, P.R. China

*) Corresponding author. e-mail: lucascheng62@gmail.com 